\title{
Seroprevalence of Antibodies to SARS-CoV-2 among Health Care Workers in Kenya
}

Anthony O. Etyang ${ }^{1}$, Ruth Lucinde ${ }^{1 \S}$, Henry Karanja $^{1 \S}$, Catherine Kalu ${ }^{1}$, Daisy Mugo ${ }^{1}$, James Nyagwange ${ }^{1}$, John Gitonga ${ }^{1}$, James Tuju ${ }^{1}$, Perpetual Wanjiku ${ }^{1}$, Angela Karani ${ }^{1}$, Shadrack

Mutua ${ }^{1}$,Hosea Maroko ${ }^{2}$, Eddy Nzomo ${ }^{3}$, Eric Maitha ${ }^{4}$, Evanson Kamuri ${ }^{5}$, Thuranira Kaugiria ${ }^{5}$, Justus Weru $^{5}$, Lucy B. Ochola ${ }^{6}$,Nelson Kilimo ${ }^{7}$, Sande Charo ${ }^{8}$, Namdala Emukule ${ }^{9}$, Wycliffe Moracha ${ }^{10}$, David Mukabi $^{10}$, Rosemary Okuku ${ }^{10}$, Monicah Ogutu ${ }^{10}$, Barrack Angujo ${ }^{1}$, Mark Otiende ${ }^{1}$, Christian Bottomley ${ }^{11}$, Edward Otieno ${ }^{1}$, Leonard Ndwiga ${ }^{1}$, Amek Nyaguara ${ }^{1}$, Shirine Voller ${ }^{1,11}$, Charles Agoti ${ }^{1}$, David James Nokes ${ }^{1}$, Lynette Isabella Ochola-Oyier ${ }^{1}$, Rashid Aman ${ }^{12}$, Patrick Amoth ${ }^{12}$, Mercy Mwangangi ${ }^{12}$, Kadondi Kasera ${ }^{12}$, Wangari $\mathrm{Ng}^{\prime}$ ang $^{\prime} \mathrm{a}^{13}$, Ifedayo Adetifa ${ }^{1,11}$, E. Wangeci Kagucia ${ }^{1}$, Katherine Gallagher ${ }^{1,11}$, Sophie Uyoga ${ }^{1}$, Benjamin Tsofa $^{1}$, Edwine Barasa ${ }^{1}$, Philip Bejon ${ }^{1,14}$, J. Anthony G. Scott ${ }^{1,11 \S}$, Ambrose Agweyu ${ }^{1 \S}$, George Warimwe ${ }^{1,14 \S}$

${ }^{1}$ KEMRI-Wellcome Trust Research Programme, Kilifi, Kenya

${ }^{2}$ KEMRI Center for Infectious and Parasitic Diseases Control Research, Alupe, Kenya

${ }^{3}$ Kilifi County Hospital, Kilifi, Kenya

${ }^{4}$ Department of Health, Kilifi County, Kenya

${ }^{5}$ Kenyatta National Hospital, Nairobi, Kenya

${ }^{6}$ Alupe Sub-County Hospital, Busia, Kenya

${ }^{7}$ Institute of Primary Research, Nairobi, Kenya

${ }^{8}$ Kocholia Sub-County Hospital, Busia, Kenya

${ }^{9}$ Busia County Referral Hospital, Busia, Kenya

${ }^{10}$ Department of Health, Busia County, Busia, Kenya

(C) The Author(s) 2021. Published by Oxford University Press for the Infectious Diseases Society of America.

This is an Open Access article distributed under the terms of the Creative Commons Attribution License (http://creativecommons.org/licenses/by/4.0/), which permits unrestricted reuse, distribution, and reproduction in any medium, provided the original work is properly cited. 
${ }^{11}$ Department of Infectious Diseases Epidemiology, London School of Hygiene and Tropical Medicine, UK

${ }^{12}$ Ministry of Health, Government of Kenya, Nairobi, Kenya

${ }^{13}$ Presidential Policy and Strategy Unit, The Presidency, Government of Kenya

${ }^{14}$ Nuffield Department of Medicine, Oxford University, UK

${ }^{\S}$ Equal contribution

Corresponding author: Anthony O. Etyang, 813, Mbuyuni Bldg, P.O. Box 230-80108, Kilifi, Kenya

Tel +254 730163000

Fax +254 417522390

Email: Aetyang@kemri-wellcome.org

\section{Article summary}

In this study of antibodies to SARS-CoV-2 among health care workers in three counties in Kenya, we found significant regional differences in seroprevalence but no differences according to professional cadre. 


\section{ABSTRACT}

\section{Background}

Few studies have assessed the seroprevalence of antibodies against SARS-CoV-2 among Health Care Workers (HCWs) in Africa. We report findings from a survey among HCWs in three counties in Kenya.

\section{Methods}

We recruited $684 \mathrm{HCWs}$ from Kilifi (rural), Busia (rural) and Nairobi (urban) counties. The serosurvey was conducted between $30^{\text {th }}$ July 2020 and $4^{\text {th }}$ December 2020 . We tested for IgG antibodies to SARS-CoV-2 spike protein using ELISA. Assay sensitivity and specificity were 93\% (95\% Cl 88-96\%) and 99\% (95\% Cl 98-99.5\%), respectively. We adjusted prevalence estimates using Bayesian modeling to account for assay performance.

\section{Results}

Crude overall seroprevalence was 19.7\% (135/684). After adjustment for assay performance seroprevalence was $20.8 \%$ (95\% Crl $17.5-24.4 \%$ ). Seroprevalence varied significantly $(\mathrm{p}<0.001)$ by site: $43.8 \%(\mathrm{Crl} 35.8-52.2 \%)$ in Nairobi, $12.6 \%(\mathrm{Crl} 8.8-17.1 \%)$ in Busia and 11.5\% (Crl 7.2-17.6\%) in Kilifi. In a multivariable model controlling for age, sex and site, professional cadre was not associated with differences in seroprevalence.

\section{Conclusion}

These initial data demonstrate a high seroprevalence of antibodies to SARS-CoV-2 among HCWs in Kenya. There was significant variation in seroprevalence by region, but not by cadre.

Key words: SARS-CoV-2; Health Care Workers; Antibodies; Seroprevalence 


\section{INTRODUCTION}

Health care workers (HCWs) are critical in the acute-care response to epidemic waves of

COVID-19, but they are also required to sustain normal health services beyond COVID-19.

HCWs are considered to be at high risk of infection with SARS-CoV- $2^{1}$. It is unclear whether the seroprevalence of SARS-CoV-2 antibodies among HCWs is more closely associated with community or hospital-based transmission risk as indicated by professional cadre. In some hospitals, seroprevalence was higher among cadres in lower paid jobs with little patient contact (e.g. housekeepers, porters) suggesting the source of infection may be their crowded living conditions rather than occupational risk ${ }^{2}$. The true extent of infection in HCWs in Kenya has been difficult to determine, due to factors including (1) the fact that a large proportion of infections (>90\%) are asymptomatic ${ }^{3}$, possibly because of the young population structure; and (2) because of challenges in PCR testing of nasal and oropharyngeal (NP/OP) swabs in Kenya ${ }^{4}$ and, indeed most low and middle-income countries (LMICs).

Serological surveys can estimate cumulative incidence of SARS-CoV-2 infection in either key groups, such as HCWs, or the general population ${ }^{5}$. They can also assess the effectiveness of infection prevention and control measures, which is important in sub-Saharan Africa (sSA) where the availability of personal protective equipment and other preventive measures is constrained. To date HCW serosurveys in SSA have been limited to urban hospitals ${ }^{6-8}$; there are no surveys from rural hospitals, where resources are even more constrained. Serosurveys on different population groups or in different geographical regions can also inform vaccine prioritization policies. This is especially important in LMICs where only a small proportion of the population are likely to receive vaccines in the early phase of the vaccine campaign ${ }^{9}$. 
Because the presence of antibodies to SARS-CoV-2 appears to be strongly protective against repeat infection over a 6-month period ${ }^{10,11}$, knowledge of past infection could be useful for avoiding unnecessary quarantines which would help preserve the limited numbers of personnel available to deal with the pandemic and other health needs in the region.

We report initial findings from SARS-CoV-2 antibody testing from HCWs in three sites in Coastal, Central, and Western Kenya.

\section{METHODS}

\section{Study sites and Participants}

Study sites (Figure S1) were selected after consultation with the individual county COVID-19 Rapid Response Teams (RRTs). For Kilifi County, a predominantly rural area located on the Indian Ocean coast, we enrolled participants at Kilifi County Hospital, which is the main referral facility in the region. For Busia County, which is also predominantly rural and located in the western region of Kenya, we enrolled HCWs at Busia County Referral Hospital, the main referral facility in the area, and two other facilities in the county; Alupe Sub-County Hospital which has been designated as the isolation facility for COVID-19 patients in the county, and Kocholia Sub-County Hospital. In Nairobi County, the capital city of Kenya, we enrolled HCWs at the Kenyatta National Hospital (KNH), the main referral facility for the city as well as the country ${ }^{12}$.

We used a variety of strategies to recruit a convenience sample of HCWs at each of the study sites, including word of mouth, advertising at hospital notice boards and messages sent via mobile phone. HCWs of all cadres were eligible to participate in the study. In Kilifi and Busia we aimed to recruit $\geq 50 \%(\mathrm{~N}=441)$ of the $882 \mathrm{HCWs}$ working in the healthcare facilities, which we considered to be both feasible and likely to provide a representative 
sample. We used a slightly different strategy at $\mathrm{KNH}$, where the primary aim of the study was to determine incidence and antibody kinetics among $180 \mathrm{HCWs,} \mathrm{comprising} \sim 4 \%$ of the hospital's estimated $5,000 \mathrm{HCWs}{ }^{12} \mathrm{l}$, who were likely (by self-report) to be available for a year-long longitudinal study.

\section{Ethics and Consents}

Serosurveillance was conducted as a public health activity requested by the Kenya Ministry of Health and ethical approval for collection and publication of these data was obtained from the Kenya Medical Research Institute Scientific and Ethics Review Unit (KEMRI/SERU/CGMR-C/203/4085). HCWs provided written and/or verbal informed consent for participation in the study. Results of the antibody testing were reported confidentially to each HCW together with information explaining the implications of the test results.

\section{Sample collection and processing}

The study took place between $30^{\text {th }}$ July 2020 and $4^{\text {th }}$ December 2020. Data collection was performed by members of staff from the participating hospitals, trained on the study procedures.

We collected $6 \mathrm{ml}$ of venous blood in sodium heparin tubes from each participant. Serum was obtained by centrifuging the samples at $450 \times \mathrm{g}$ for 5 minutes before storage at $-80 \circ \mathrm{C}$. Samples were then transported in dry ice to the KEMRI-Wellcome Trust research laboratories in Kilifi for assays.

A simple one-page questionnaire (provided in the appendix) was administered to the HCWs either electronically or on paper, in which data on demographic and clinical characteristics were collected. 


\section{ELISA for SARS-CoV-2 Spike Protein}

All samples were tested at the KWTRP laboratories in Kilifi for IgG to SARS-CoV-2 whole spike protein using an adaptation of the Krammer Enzyme Linked Immunosorbent Assay $(E L I S A)^{13}$. We assumed an assay sensitivity of $92.7 \%(95 \% \mathrm{Cl} 87.9-96.1 \%)$ and specificity of 99.0\% (95\% Cl 98.1-99.5) based on validation studies that we had previously conducted ${ }^{14}$. Results were expressed as the ratio of test OD to the OD of the plate negative control; samples with OD ratios greater than two were considered positive for SARS-CoV-2 IgG.

\section{Statistical methods}

Continuous variables were summarized as means and standard deviations if normally distributed and medians with interquartile ranges for non-normally distributed variables.

Categorical data were presented as counts and percentages. Bayesian modelling was used to adjust seroprevalence estimates for the sensitivity and specificity of the assay. Noninformative priors were used for all parameters, and the models were fitted using the Rstan software package ${ }^{15}$ (see appendix for code). We tested for associations between seroprevalence and professional cadre and site, respectively using multivariable logistic regression.

All analyses were conducted using Stata ${ }^{\mathrm{TM}}$ Version 15 software (College Station, Texas, USA) and $R$ version 3.6.1 (Vienna, Austria).

\section{RESULTS}

We recruited $684 \mathrm{HCWs}$ from Nairobi, Busia and Kilifi (Figure S2 and Table 1). The numbers of the HCWs that we recruited as a proportion of total number of staff at the facilities were $70 \%$ in Kilifi, $50 \%$ in Busia, and $\sim 4 \%$ in Nairobi. The mean age \pm SD of the participants was 35 
\pm 11 years and $54 \%$ were female. Sixteen (2\%) of the HCWs reported that they had acute respiratory symptoms at the time of sample collection.

Out of the 684 HCWs, 135 (19.7\%) were seropositive for antibodies to SARS-CoV-2 (Table 2). After adjusting for test performance characteristics, the seroprevalence was $20.8 \%$ ( $95 \%$ Credible Interval 17.5-24.4). Adjusted seroprevalence among the different cadres ranged from $12.5 \%$ (95\% Cr I 5.4-21.8) among Clinical Officers to 34.2\% (95\% Crl 23.7-45.8) among doctors. There was a higher seroprevalence among HCWs in Nairobi $(43.8 \%, 95 \% \mathrm{Crl} 35.8$ 52.2) compared with Kilifi (11.9\%, 95\% Crl 7.2-17.6) and Busia (12.6\%, 95\% Crl 8.8-17.1).

Table 3 displays the results of univariable and multivariable logistic regression modeling testing associations between participant characteristics and seroprevalence. The only exposure variable that displayed a statistically significant association with seroprevalence in the multivariable model was site; HCWs in Kilifi (OR 0.2, 95\% Cl 0.1-0.3) and Busia (OR 0.2, $95 \% \mathrm{Cl} 0.1-0.4)$ were less likely to be seropositive compared to those in Nairobi. Professional cadre, age and sex were not associated with seroprevalence in both univariable and multivariable analyses. Site-specific analyses also did not reveal any association between seroprevalence and professional cadre (Table S1).

\section{DISCUSSION}

We report results of a SARS-CoV-2 seroprevalence study conducted among HCWs in 3 counties in Kenya. We found an overall seroprevalence of SARS-CoV-2 antibodies of $20.8 \%$ (95\% Crl 17.5-24.4\%). There were significant differences in seroprevalence associated with hospital region, but no differences associated with professional cadre.

Our estimates of seroprevalence are higher than what was found in most of studies from Africa that have been published to date, all of which were conducted in urban areas ${ }^{6-8,16}$ and 
had a pooled seroprevalence of $8.2 \%(95 \% \mathrm{Cl} 0.8-22.3)^{17}$. We conducted our study during and shortly after the first wave of the epidemic in Kenya ${ }^{4}$, while the previous studies in Africa were conducted relatively early in the epidemic. Our estimates are similar to those observed among HCWs in several high-income countries at the peak of their first wave of the epidemic ${ }^{17}$.

Consistent with other studies conducted in Kenya ${ }^{4,14,18-20}$, we found significant differences in seroprevalence by region. HCWs in urban Nairobi had significantly higher seroprevalence than those in Busia and Kilifi, which are rural counties. Studies in Spain and India have also shown significant regional differences, with higher seroprevalence in urban areas, such as Madrid and New Delhi, compared to rural areas ${ }^{21,22}$. However, even in the rural counties in Kenya, HCWs had seroprevalence estimates that were similar to those in HCWs in urban areas in Spain ${ }^{23}$, USA $^{24}$ and Malawi ${ }^{6}$.

We found no differences in seroprevalence by professional category even when the analyses were stratified by study site. The absence of differences in seroprevalence by cadre in the presence of significant differences by geographical region suggests that community transmission could be playing a bigger role than workplace exposure. In studies of HCWs conducted in the UK, the incidence of infection mirrored that seen in the community ${ }^{2,25}$. This suggests that efforts to suppress community transmission are likely to reduce infections among HCWs.

The results of this study provide further evidence that there has been significant undocumented transmission of the SARS-CoV-2 virus within Kenya. Additional evidence of significant undocumented transmission in Kenya derives from (1) two studies of seroprevalence among blood transfusion donors ${ }^{14,18} ;(2)$ a study of truck drivers and their assistants conducted at the same time as this survey in Kilifi and Busia that found a seroprevalence of $42 \%{ }^{19}$, and; (3) In a study of antenatal clinic attendees, seroprevalence 
was $50 \%$ at Kenyatta National Hospital in August 2020, and $11 \%$ at Kilifi County Hospital in November $2020^{20}$

A particular strength of this study is that we conducted it in several sites, which enabled us to detect a significant burden of infection among HCWs in rural parts of the country. Another strength is that we used an assay that was validated using both local and external samples and which performed well in a WHO-sponsored international standardization study $^{26}$. Although we adjusted our figures using Bayesian modelling to take into account assay performance, the reported seroprevalence could still be underestimated due to antibody waning ${ }^{27}$. The longitudinal phase of the current study will help address this issue. Another possible reason for underestimation of the prevalence in our study would be spectrum bias $^{28}$ since the samples that we used in validating the assay, although derived from the local population, these individuals were not necessarily the same as the HCWs that participated in the present survey.

Our study had several limitations. We did not perform genetic sequencing to establish the likely sources of infections among the HCWs, although as argued above, the data we obtained suggests that community transmission was the main driver of infections among the HCWs. The non-random selection of only a small proportion of the HCWs in Nairobi could have led to an overestimation of the seroprevalence if the HCWs sampled had an overrepresentation of individuals who had experienced symptoms in the past. However, this would have also resulted in a higher proportion of HCWs in Nairobi having positive results from previously conducted PCR tests, but we did not observe this. In addition a household survey found that $35 \%$ of the population in Nairobi had antibodies to SARS-CoV- $2^{29}$, and the rural-urban difference in seroprevalence among $\mathrm{HCW}$ s that we observed was similar to what has been observed in other studies conducted in Kenya ${ }^{14,18-20}$. 
In conclusion, we found a high prevalence of antibodies to SARS-CoV-2 among HCWs in Kenya, with significant regional differences and no differences based on cadre. The results suggest that infection with SARS-CoV-2 among HCWs is driven more by background population levels of infection than workplace exposure and will be useful in informing measures to control the on-going pandemic. 


\section{Acknowledgments}

We would like to thank all HCWs who participated in the study as well as the county health teams and the Kenya Paediatric Research Consortium (KEPRECON) that facilitated data collection for the study. We thank F. Krammer for providing the plasmids used to generate the RBD, spike protein, and CR3022 monoclonal antibody used in this work. Development of SARS-CoV-2 reagents was partially supported by the NIAID Centres of Excellence for Influenza Research and Surveillance (CEIRS) contract HHSN272201400008C. The COVID-19 convalescent plasma panel (NIBSC 20/118) and research reagent for SARS-CoV-2 Ab (NIBSC 20/130) were obtained from the NIBSC, UK. We also thank the WHO SOLIDARITY II network for sharing of protocols and for facilitating the development and distribution of control reagents. This manuscript was written with the permission of the Director, KEMRI-CGMRC.

\section{Funding}

This project was funded by the Wellcome Trust (grants 220991/Z/20/Z and 203077/Z/16/Z), the Bill and Melinda Gates Foundation (INV-017547), and the Foreign Commonwealth and Development Office (FCDO) through the East Africa Research Fund (EARF/ITT/039) and is part of an integrated programme of SARS-CoV-2 serosurveillance in Kenya led by KEMRI Wellcome Trust Research Programme. For the purpose of Open Access, the author has applied a CC-BY public copyright licence to any author accepted manuscript version arising from this submission.

A.A. is funded by a DFID/MRC/NIHR/Wellcome Trust Joint Global Health Trials Award (MR/R006083/1), J.A.G.S. is funded by a Wellcome Trust Senior Research Fellowship (214320) and the NIHR Health Protection Research Unit in Immunisation. I.M.O.A. is funded by the United Kingdom's Medical Research Council and Department For International Development through an African Research Leader Fellowship (MR/S005293/1) and by the 
NIHR-MPRU at UCL (grant 2268427 LSHTM). G.M.W. is supported by a fellowship from the Oak Foundation. C.N.A. is funded by the DELTAS Africa Initiative [DEL-15-003], and the Department for International Development and Wellcome (220985/Z/20/Z). S.U. is funded by DELTAS Africa Initiative [DEL-15-003], L.I.O-O. is funded by a Wellcome Trust Intermediate Fellowship (107568/Z/15/Z).

\section{Conflicts of Interest/Disclosures}

J.A.G.S. reports grants form Bill \& Melinda Gates Foundation and Gavi, The Vaccine Alliance, outside the submitted work. No other authors have any conflicts of interest or disclosures to report. 


\section{REFERENCES}

1. Chou R, Dana T, Buckley DI, Selph S, Fu R and Totten AM. Epidemiology of and Risk Factors for Coronavirus Infection in Health Care Workers: A Living Rapid Review. Ann Intern Med. 2020;173:120-136.

2. Shields A, Faustini SE, Perez-Toledo M, Jossi S, Aldera E, Allen JD, Al-Taei S, Backhouse C, Bosworth A, Dunbar LA, Ebanks D, Emmanuel B, Garvey M, Gray J, Kidd IM, McGinnell G, McLoughlin DE, Morley G, O'Neill J, Papakonstantinou D, Pickles O, Poxon C, Richter M, Walker EM, Wanigasooriya K, Watanabe Y, Whalley C, Zielinska AE, Crispin M, Wraith DC, Beggs AD, Cunningham AF, Drayson MT and Richter AG. SARS-CoV-2 seroprevalence and asymptomatic viral carriage in healthcare workers: a cross-sectional study. Thorax. 2020;75:1089-1094.

3. Kenya MoH. Kenyan Ministry of Health: COVID-19 situation reports https://www.health.go.ke/\#1591180376422-52af4c1e-256b

4. Ojal J, Brand SPC, Were V, Okiro EA, Kombe IK, Mburu C, Aziza R, Ogero M, Agweyu A, Warimwe GM, Uyoga S, Adetifa IMO, Scott JA, Otieno E, OcholaOyier LI, Agoti CN, Kasera K, Amoth P, Mwangangi M, Aman R, Ng'ang'a W, Tsofa B, Bejon P, Barasa E, Keeling MJ and Nokes DJ. Revealing the extent of the COVID19 pandemic in Kenya based on serological and PCR-test data. medRxiv. 2020:2020.09.02.20186817.

5. Alter $\mathrm{G}$ and Seder R. The Power of Antibody-Based Surveillance. N Engl J Med. 2020;383:1782-1784.

6. Chibwana MG, Jere KC, Kamng'ona R, Mandolo J, Katunga-Phiri V, Tembo D, Mitole N, Musasa S, Sichone S, Lakudzala A, Sibale L, Matambo P, Kadwala I, Byrne RL, Mbewe A, Henrion MYR, Morton B, Phiri C, Mallewa J, Mwandumba HC, Adams ER, Gordon SB and Jambo KC. High SARS-CoV-2 seroprevalence in health care workers but relatively low numbers of deaths in urban Malawi [version 2; peer review: 2 approved]. Wellcome Open Res. 2020;5:199.

7. Olayanju O, Bamidele O, Edem F, Eseile B, Amoo A, Nwaokenye J, Udeh C, Oluwole G, Odok G and Awah N. SARS-CoV-2 Seropositivity in Asymptomatic Frontline Health Workers in Ibadan, Nigeria. Am J Trop Med Hyg. 2021;104:91-94. 8. Mukwege D, Byabene AK, Akonkwa EM, Dahma H, Dauby N, Cikwanine Buhendwa JP, Le Coadou A, Montesinos I, Bruyneel M, Cadiere GB, Vandenberg O 
and Van Laethem Y. High SARS-CoV-2 Seroprevalence in Healthcare Workers in Bukavu, Eastern Democratic Republic of Congo. Am J Trop Med Hyg. 2021:1-5. 9. Yamey G, Schaferhoff M, Hatchett R, Pate M, Zhao F and McDade KK. Ensuring global access to COVID-19 vaccines. Lancet. 2020;395:1405-1406.

10. Lumley SF, O'Donnell D, Stoesser NE, Matthews PC, Howarth A, Hatch SB, Marsden BD, Cox S, James T, Warren F, Peck LJ, Ritter TG, de Toledo Z, Warren L, Axten D, Cornall RJ, Jones EY, Stuart DI, Screaton G, Ebner D, Hoosdally S, Chand M, Crook DW, O'Donnell AM, Conlon CP, Pouwels KB, Walker AS, Peto TEA, Hopkins S, Walker TM, Jeffery K, Eyre DW and Oxford University Hospitals Staff Testing G. Antibody Status and Incidence of SARS-CoV-2 Infection in Health Care Workers. N Engl J Med. 2020:NEJMoa2034545-NEJMoa2034545.

11. Hall V, Foulkes S, Charlett A, Atti A, Monk EJM, Simmons R, Wellington E, Cole MJ, Saei A, Oguti B, Munro K, Wallace S, Kirwan PD, Shrotri M, Vusirikala A, Rokadiya S, Kall M, Zambon M, Ramsay M, Brooks T, Brown CS, Chand MA and Hopkins S. Do antibody positive healthcare workers have lower SARS-CoV-2 infection rates than antibody negative healthcare workers? Large multi-centre prospective cohort study (the SIREN study), England: June to November 2020. medRxiv. 2021:2021.01.13.21249642.

12. KNH. Kenyatta National Hospital Strategic Plan 2018-2023 Available at https://knh.or.ke/publications/strategic plan/2018/KNH Strategic Plan-20182023 FINAL.pdf.

13. Amanat F, Stadlbauer D, Strohmeier S, Nguyen THO, Chromikova V, McMahon M, Jiang K, Arunkumar GA, Jurczyszak D, Polanco J, Bermudez-Gonzalez M, Kleiner G, Aydillo T, Miorin L, Fierer DS, Lugo LA, Kojic EM, Stoever J, Liu STH, Cunningham-Rundles C, Felgner PL, Moran T, Garcia-Sastre A, Caplivski D, Cheng AC, Kedzierska K, Vapalahti O, Hepojoki JM, Simon V and Krammer F. A serological assay to detect SARS-CoV-2 seroconversion in humans. Nat Med. 2020;26:10331036.

14. Uyoga S, Adetifa IMO, Karanja HK, Nyagwange J, Tuju J, Wanjiku P, Aman R, Mwangangi M, Amoth P, Kasera K, Ng'ang'a W, Rombo C, Yegon C, Kithi K, Odhiambo E, Rotich T, Orgut I, Kihara S, Otiende M, Bottomley C, Mupe ZN, Kagucia EW, Gallagher KE, Etyang A, Voller S, Gitonga JN, Mugo D, Agoti CN, Otieno E, Ndwiga L, Lambe T, Wright D, Barasa E, Tsofa B, Bejon P, Ochola-Oyier LI, Agweyu A, Scott JAG and Warimwe GM. Seroprevalence of anti-SARS-CoV-2 $\lg \mathrm{G}$ antibodies in Kenyan blood donors. Science. 2020:eabe1916-eabe1916. 
15. Stan Development Team. RStan: the $R$ interface to Stan. $R$ package version 2.21. 2, http://mc-stan.org/. 2020.

16. Kammon AM, El-Arabi AA, Erhouma EA, Mehemed TM and Mohamed OA. Seroprevalence of antibodies against SARS-CoV-2 among public community and health-care workers in Alzintan City of Libya. medRxiv. 2020:2020.05.25.20109470. 17. Galanis P, Vraka I, Fragkou D, Bilali A and Kaitelidou D. Seroprevalence of SARS-CoV-2 antibodies and associated factors in health care workers: a systematic review and meta-analysis. J Hosp Infect. 2020;108:120-134.

18. Adetifa IMO, Uyoga S, Gitonga JN, Mugo D, Otiende M, Nyagwange J, Karanja HK, Tuju J, Wanjiku P, Aman R, Mwangangi M, Amoth P, Kasera K, Ng'ang'a W, Rombo C, Yegon C, Kithi K, Odhiambo E, Rotich T, Orgut I, Kihara S, Bottomley C, Kagucia EW, Gallagher KE, Etyang A, Voller S, Lambe T, Wright D, Barasa E, Tsofa B, Bejon P, Ochola-Oyier LI, Agweyu A, Scott JAG and Warimwe GM. Temporal trends of SARS-CoV-2 seroprevalence in transfusion blood donors during the first wave of the COVID-19 epidemic in Kenya. medRxiv. 2021:2021.02.09.21251404.

19. Kagucia EW, Gitonga JN, Kalu C, Ochomo E, Ochieng B, Kuya N, Karani A, Nyagwange J, Karia B, Mugo D, Karanja HK, Tuju J, Mutiso A, Maroko H, Okubi L, Maitha E, Ajuck H, Bogita M, Mudindi R, Mukabi D, Moracha W, Bulimu D, Andanje N, Shiraku E, Okuku R, Ogutu M, Aman R, Mwangangi M, Amoth P, Kasera K, Ng, ang, a W, Mariga R, Munabi T, Ramadhan SM, Mwikali J, Nasike R, Andera C, Nechesa R, Kiplagat BK, Omengo J, Oteba S, Mwangi A, Mkanyi D, Karisa G, Migosi JK, Msili P, Mwambire S, Boniface AM, Nyaguara A, Voller S, Otiende M, Bottomley C, Agoti CN, Ochola-Oyier LI, Adetifa IMO, Etyang AO, Gallagher KE, Uyoga S, Barasa E, Bejon P, Tsofa B, Agweyu A, Warimwe GM and Scott JAG.

Seroprevalence of anti-SARS-CoV-2 IgG antibodies among truck drivers and assistants in Kenya. medRxiv. 2021:2021.02.12.21251294.

20. Lucinde R, Mugo D, Bottomley C, Aziza R, Gitonga J, Karanja H, Nyagwange J, Tuju J, Wanjiku P, Nzomo E, Kamuri E, Thuranira K, Agunda S, Nyutu G, Etyang A, Adetifa IMO, Kagucia E, Uyoga S, Otiende M, Otieno E, Ndwiga L, Agoti CN, Aman R, Mwangangi M, Amoth P, Kasera K, Nyaguara A, Ng'ang'a W, Ochola LB, Barasa E, Bejon P, Tsofa B, Ochola-Oyier LI, Warimwe GM, Agweyu A, Scott JAG and Gallagher KE. Sero-surveillance for IgG to SARS-CoV-2 at antenatal care clinics in two Kenyan referral hospitals. medRxiv. 2021:2021.02.05.21250735.

21. Pollan M, Perez-Gomez B, Pastor-Barriuso R, Oteo J, Hernan MA, PerezOlmeda M, Sanmartin JL, Fernandez-Garcia A, Cruz I, Fernandez de Larrea N, Molina M, Rodriguez-Cabrera F, Martin M, Merino-Amador P, Leon Paniagua J, 
Munoz-Montalvo JF, Blanco F, Yotti R and Group E-CS. Prevalence of SARS-CoV-2 in Spain (ENE-COVID): a nationwide, population-based seroepidemiological study. Lancet. 2020;396:535-544.

22. Murhekar MV, Bhatnagar T, Selvaraju S, Saravanakumar V, Thangaraj JWV, Shah N, Kumar MS, Rade K, Sabarinathan R, Asthana S, Balachandar R, Bangar SD, Bansal AK, Bhat J, Chopra V, Das D, Deb AK, Devi KR, Dwivedi GR, Khan SMS, Kumar CPG, Kumar MS, Laxmaiah A, Madhukar M, Mahapatra A, Mohanty SS, Rangaraju C, Turuk A, Baradwaj DK, Chahal AS, Debnath F, Haq I, Kalliath A, Kanungo S, Kshatri JS, Lakshmi G, Mitra A, Nirmala AR, Prasad GV, Qurieshi MA, Sahay S, Sangwan RK, Sekar K, Shukla VK, Singh PK, Singh P, Singh R, Varma DS, Viramgami A, Panda S, Reddy DCS, Bhargava B and Group IS. SARS-CoV-2 antibody seroprevalence in India, August-September, 2020: findings from the second nationwide household serosurvey. Lancet Glob Health. 2021:1-10.

23. Garcia-Basteiro AL, Moncunill G, Tortajada M, Vidal M, Guinovart C, Jimenez A, Santano R, Sanz S, Mendez S, Llupia A, Aguilar R, Alonso S, Barrios D, Carolis C, Cistero P, Choliz E, Cruz A, Fochs S, Jairoce C, Hecht J, Lamoglia M, Martinez MJ, Mitchell RA, Ortega N, Pey N, Puyol L, Ribes M, Rosell N, Sotomayor P, Torres S, Williams S, Barroso S, Vilella A, Munoz J, Trilla A, Varela P, Mayor A and Dobano C. Seroprevalence of antibodies against SARS-CoV-2 among health care workers in a large Spanish reference hospital. Nat Commun. 2020;11:3500.

24. Moscola J, Sembajwe G, Jarrett M, Farber B, Chang T, McGinn T, Davidson KW and Northwell Health C-RC. Prevalence of SARS-CoV-2 Antibodies in Health Care Personnel in the New York City Area. JAMA. 2020;324:893-895.

25. Treibel TA, Manisty C, Burton M, McKnight Á, Lambourne J, Augusto JB, Couto-Parada X, Cutino-Moguel T, Noursadeghi M and Moon JC. COVID-19: PCR screening of asymptomatic health-care workers at London hospital. The Lancet. 2020;395:1608-1610.

26. Giada Mattiuzzo EMB, Mark Hassall, Stephanie Routley, Samuel

Richardson, Valentina Bernasconi, Paul Kristiansen, Heli Harvala, David Roberts, Malcom G Semple , Lance CW Turtle, Peter JM Openshaw and Kenneth Baillie on behalf of the ISARICC Investigators, Lise Sofie Haug Nissen-Meyer, Arne Broch Brantsæter, Helen Baxendale, Eleanor Atkinson, Peter Rigsby, David Padley, Neil Almond, Nicola J. Rose, Mark Page and the collaborative study participants Establishment of the WHO International Standard and Reference Panel for antiSARS-CoV-2 antibody. 2020.

27. Ward H, Cooke G, Atchison C, Whitaker M, Elliott J, Moshe M, Brown JC, Flower B, Daunt A, Ainslie K, Ashby D, Donnelly C, Riley S, Darzi A, Barclay W and 
Elliott P. Declining prevalence of antibody positivity to SARS-CoV-2: a community study of 365,000 adults. medRxiv. 2020:2020.10.26.20219725.

28. Takahashi S, Greenhouse B and Rodriguez-Barraquer I. Are Seroprevalence Estimates for Severe Acute Respiratory Syndrome Coronavirus 2 Biased? J Infect Dis. 2020;222:1772-1775.

29. Makayotto L, Oluga O and Osoro E. Policy Brief: Findings of COVID-19 Antibody Survey in Nairobi City County Conducted in November 2020. 2021. 
Table 1: Characteristics of study participants

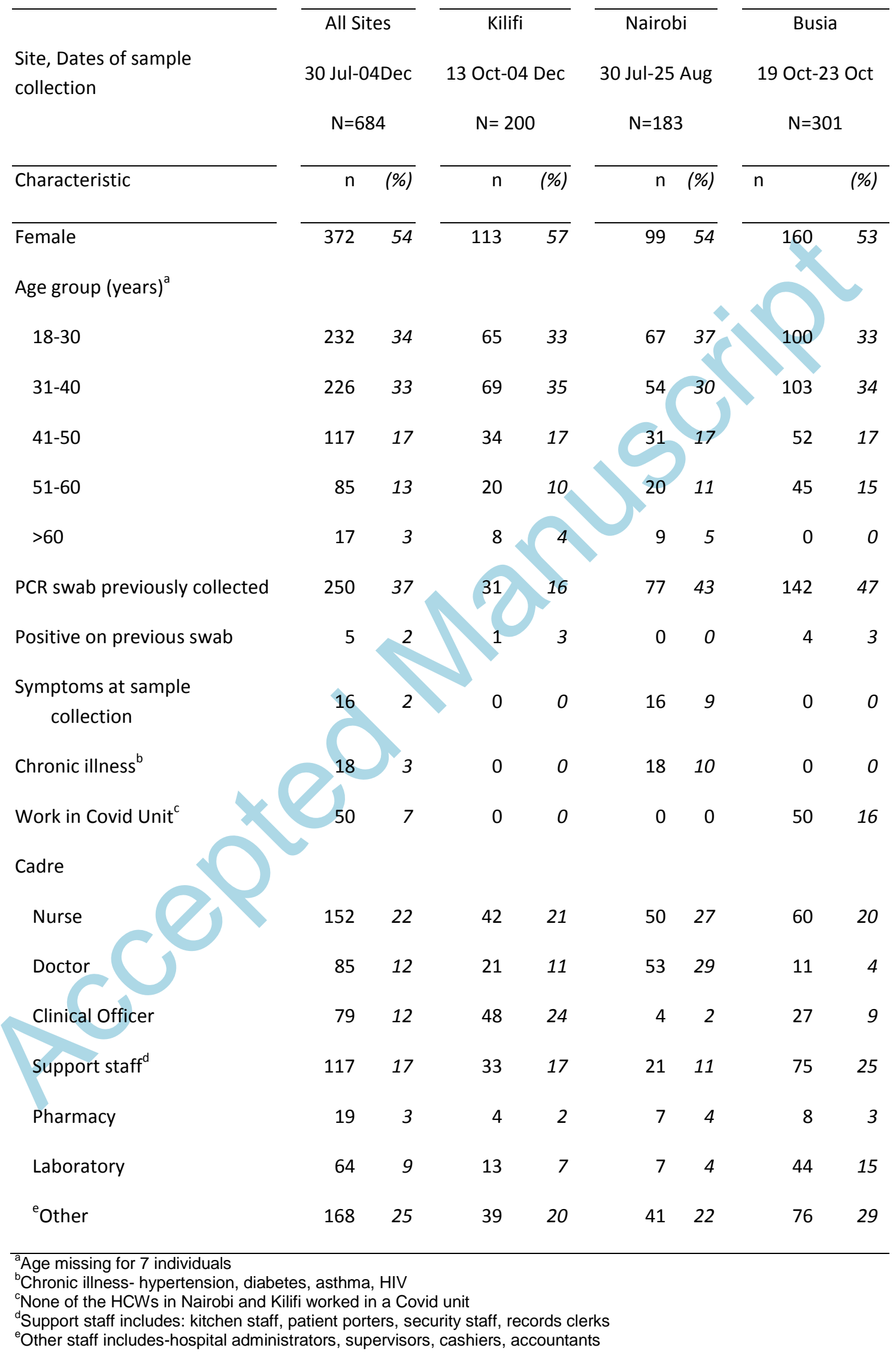


Table 2: Seroprevalence of antibodies to SARS-CoV-2 by participant characteristics

\begin{tabular}{|c|c|c|c|c|c|}
\hline & $\mathrm{N}$ & Sero & Crude sero- & Adju & oprevalence \\
\hline & & positive & pievalemice & $\%$ & (95\% Crl) \\
\hline Age group (year & & & & & \\
\hline $18-30$ & 232 & 49 & 21.1 & 22.1 & $(16.5-28.5)$ \\
\hline $31-40$ & 226 & 46 & 20.4 & 21.6 & $(15.8-27.8)$ \\
\hline $41-50$ & 117 & 20 & 17.1 & 18.3 & \\
\hline $51-60$ & 85 & 15 & 17.7 & 18.8 & (10.9-28.5) \\
\hline$>60$ & 17 & 4 & 23.5 & & $(9.3-50.8)$ \\
\hline Sex & & & & & \\
\hline Female & 372 & 69 & 18.6 & 19.3 & $(15.1-24.1)$ \\
\hline Male & 312 & 66 & 21.2 & 22.1 & (17.2-27.7) \\
\hline Cadre & & & & & \\
\hline Nurse & 152 & 29 & 19.1 & 20.2 & (13.8-27.9) \\
\hline Doctor & 85 & 27 & 31.8 & 34.2 & $(23.7-45.8)$ \\
\hline Clinical Officer & 9 & 9 & 11.3 & 12.5 & (5.4-21.8) \\
\hline Support staff & 117 & 25 & 21.3 & 22.9 & $(15.2-31.6)$ \\
\hline Pharmacy & 19 & 5 & 26.3 & 30.3 & (11.3-51.9) \\
\hline Laboratory & 64 & 12 & 18.8 & 20.4 & (10.6-31.5) \\
\hline Other & 168 & 28 & 16.7 & 17.5 & $(11.8-24.3)$ \\
\hline Site & & & & & \\
\hline Kilifi & 200 & 23 & 11.5 & 11.9 & (7.2-17.6) \\
\hline Nairobi & 183 & 75 & 41.0 & 43.8 & (35.8-52.2) \\
\hline Busia & 301 & 37 & 12.3 & 12.6 & (8.8-17.1) \\
\hline Total & 684 & 135 & 19.7 & 20.8 & $(17.5-24.4)$ \\
\hline
\end{tabular}


Table 3: Univariable and multivariable analysis of factors associated with presence of antibodies to SARS-CoV-2

\begin{tabular}{|c|c|c|c|c|}
\hline \multirow{2}{*}{$\begin{array}{l}\text { Characteristic } \\
\text { Sex }\end{array}$} & \multicolumn{2}{|c|}{ Univariable } & \multicolumn{2}{|c|}{ Multivariable $^{\S}$} \\
\hline & OR & $(95 \% \mathrm{Cl})$ & OR & $(95 \% \mathrm{Cl})$ \\
\hline Female & 1.0 & - & 1.0 & - \\
\hline Male & 1.18 & $(0.81-1.71)$ & 1.13 & $(0.75-1.72)$ \\
\hline Age (per decade) & 1.00 & $(0.98-1.01)$ & 0.99 & $(0.98-1.01)$ \\
\hline \multicolumn{5}{|l|}{ Site } \\
\hline Nairobi & 1.0 & - & & - \\
\hline Kilifi & 0.19 & $(0.11-0.32)$ & & $(0.10-0.33)$ \\
\hline Busia & 0.20 & $(0.13-0.32)$ & 0.21 & $(0.13-0.36)$ \\
\hline Working in Covid unit & 0.33 & $(0.12-0.94)$ & 0.51 & $(0.17-1.55)$ \\
\hline \multicolumn{5}{|l|}{ Symptoms at sample } \\
\hline collection & 1.98 & $(1.08-3.63)$ & 1.34 & $(0.78-2.30)$ \\
\hline Chronic illness & 2.49 & $(0.88-6.97)$ & 0.91 & $(0.30-2.72)$ \\
\hline \multicolumn{5}{|l|}{ Cadre } \\
\hline Nurse & 1.0 & - & 1.0 & - \\
\hline Doctor & 1.97 & $(1.07-3.63)$ & 1.20 & $(0.61-2.35)$ \\
\hline Clinical Officer & 0.55 & $(0.24-1.21)$ & 0.97 & $(0.41-2.30)$ \\
\hline Support staff & 1.15 & (0.63-2.09) & 1.56 & $(0.80-3.07)$ \\
\hline Pharmacy & 1.51 & $(0.51-4.54)$ & 1.50 & $(0.45-4.97)$ \\
\hline Laboratory & 0.98 & $(0.46-2.06)$ & 1.45 & $(0.64-3.27)$ \\
\hline Other & 0.85 & $(0.48-1.50)$ & 0.97 & $(0.53-1.81)$ \\
\hline
\end{tabular}

${ }^{\S}$ Adjusted for all variables in table 